\title{
OS DISCURSOS DO EMPREENDEDORISMO NA ADMINISTRAÇÃO PÚBLICA BRASILEIRA: ANÁLISE CRÍTICA DE UMA EXPERIÊNCIA CONTEMPORÂNEA
}

\author{
THE DISCOURSES OF ENTREPRENEURSHIP IN \\ BRAZILIAN PUBLIC ADMINISTRATION: CRITICAL \\ ANALYSIS OF A CONTEMPORARY EXPERIENCE
}

Data de submissão: 04/04/2014 Aceite: $21 / 05 / 2016$

Josiel Lopes Valadares ${ }^{1}$ Valderí de Castro Alcântara ${ }^{2}$

Ana Alice Vilas Boas ${ }^{3}$

Magnus Luiz Emmendoerfer ${ }^{4}$

\section{RESUMO}

Esta pesquisa tem como objetivo analisar os elementos da prática social presentes no discurso de incorporação do empreendedorismo na recente experiência do setor público de Minas Gerais, denominada Choque de Gestão. Para isso, selecionou-se um corpus oriundo de dados bibliográficos e documentais, o qual foi analisado mediante o enfoque teórico-metodológico da Análise de Discurso Crítica (ADC). Os resultados destacam o Choque de Gestão como elemento ideológico de legitimação da cultura do management no setor público por meio do discurso hegemônico neoliberal. Ao utilizar essa estratégia, a Administração Pública passa a ser permeada pela lógica do mercado (like a business), que a transforma em um ambiente de concorrência e busca por resultados, acarretando problemas típicos do modus operandi capitalista. Nesse sentido, por meio do choque, difunde-se a cultura do management, naturalizando os valores e as práticas do mundo dos negócios e legitimando discursivamente este modelo como opção necessária e viável (os ditos), ao mesmo tempo em que apaga as inconsistências, limitações e mazelas do processo (os silêncios). Neste artigo, questionamos esses caminhos e ressaltamos a importância dos processos de democratização pautados na cidadania, na participação e na deliberação.

Palavras-chave: Empreendedorismo; Setor público; Gerencialismo; Discursos.

\footnotetext{
1 Possui graduação em Administração pela Universidade Federal de Viçosa, UFV, mestrado em Administração pela Universidade Federal de Viçosa, UFV, e doutorado em Administração pela Universidade Federal de Lavras, UFLA. Atua como Professor Adjunto no Departamento de Administração e Contabilidade (DAD) da Universidade Federal de Viçosa (UFV). Viçosa, MG. E-mail: adm_josiel@yahoo.com.br

1 Possui graduação em Administração pela Universidade Federal de Viçosa - Campus de Rio Paranaíba, UFV-CRP, mestrado em Administração pela Universidade Federal de Lavras, UFLA, e doutorado em andamento em Administração pela Universidade Federal de Lavras, UFLA. Atualmente é doutorando do Programa de Pós-Graduação em Administração da Universidade Federal de Lavras (UFLA). Lavras, Brasil. E-mail: valderi.alcantara@posgrad.ufla.br

3 Possui graduação em Administração Rural pela Universidade Federal de Lavras, UFLA, mestrado em Administração pela Universidade Federal de Lavras, UFLA e doutorado em Administração pela The University of Reading, UR. Lavras, MG. E-mail: anaalice2006@oi.com.br 4 Possui graduação em Administração pela Universidade Federal de Santa Catarina, UFSC, mestrado em Administração pela Universidade Federal de Santa Catarina, UFSC e doutorado em Sociologia e Política pela Universidade Federal de Minas Gerais, UFMG. Professor Associado e Pesquisador no Departamento de Administração e Contabilidade da Universidade Federal de Vicosa (UFV) com atuação no Programa de Pós-graduação em Administração - Mestrado, Doutorado e Pós-Doutorado com concentração em Administração Pública, onde é o atual Coordenador (2016-2019). Viçosa, MG. E-mail: magnus@ufv.br
} 


\section{ABSTRACT}

This research aims to analyze the elements of social practice within the incorporation discourse of entrepreneurship in the recent experience of the public sector in the State of Minas Gerais. Data were collected on bibliographic and documentary data, using the theoretical and methodological approach of Critical Discourse Analysis (CDA). As a result, the Management Shock appears an ideological element that legitimizes the culture of management in the public sector through the neoliberal hegemonic discourse. By using this strategy, the Public Administration becomes permeated by the market logic that transforms it into a competitive and results searching environment causing typical problems of the capitalist modus operandi. In this regard, the shock spreads the culture of management, naturalizing the values and practices of the business world and discursively legitimizes this model as a necessary and viable option (what is said), while erasing inconsistencies, limitations and ills of the process (silences). In this article these pathways are questioned and the importance of democratization processes lined by citizenship, participation and deliberation is emphasized.

Keywords: Entrepreneurship; Public Sector; Managerialism; Discourses.

\section{INTRODUÇÃO}

Embora as discussões sobre a New Public Management, o empreendedorismo e o neoliberalismo sejam amplas na literatura nacional e internacional (ABRUCIO, 1998; ANDREWS; KOUZMIN, 1998; PAES DE PAULA, 2005; KETTL, 2006; DIEFENBACH, 2011; VALADARES; EMMENDOERFER, 2012), pretendemos avançar nos debates sobre o tema mediante o enfoque teóricometodológico da Análise de Discurso Crítica (ADC). Este trabalho parte, assim, do pressuposto de que "os discursos não apenas refletem as relações sociais, mas antes as constroem", de que "nenhuma linguagem é neutra, e que determinados usos da linguagem e de outras formas simbólicas são ideológicos" (COSTA; BARROS; CARVALHO, 2011, p. 181). Entendemos que os discursos são capazes de criar, legitimar e manter relações de poder (FAIRCLOUGH, 2001) - o termo discurso está sendo utilizado aqui para destacar a "linguagem como forma de prática social e não como atividade puramente individual ou reflexo de variáveis situacionais" (FAIRCLOUGH, 2001, p. 90).

No que concerne especificamente à incorporação do empreendedorismo na Administração Pública no Brasil, esta tem sido marcada por uma via ideológica e hegemônica advinda do pensamento neoliberal que se fez presente na Reforma do Estado brasileiro na década de 1990 (ANDREWS; KOUZMIN, 1998; MORAES, 2002; PAES DE PAULA, 2005; CARINHATO, 2008; LEME, 2010). Na perspectiva de Andrews e Kouzmin (1998), a força desse pensamento é evidenciada pela adoção desse discurso em termos globais pelos governos contemporâneos, tornando-se uma narrativa hegemônica (MORAES, 2002). Além disso, para Andrews e Kouzmin (1998), Moraes (2002), Paes de Paula (2005) e Kettel (2006), o discurso do neoliberalismo materializou-se nas diversas experiências reformistas que aconteceram a partir da segunda metade do século XX no Reino Unido, nos Estados Unidos, na Nova Zelândia, na Austrália, no Canadá e no Brasil, entre outros países. A primazia do pensamento neoliberal caminhou junto com a incorporação de práticas gerenciais pelo setor público, propiciando a incorporação da cultura do management ou do gerencialismo na Administração Pública (DIEFENBACH, 2009).

Quando a cultura do management "adentra as portas" do setor público, segundo Paes de Paula (2005), não se avança no sentido da democracia, pois as experiências reformistas não são suficientes para afetar a dimensão sociopolítica da Administração Pública. A autora mostra, também, que a experiência brasileira resultou na inadequação de técnicas e práticas, na centralização de poder e no afastamento do interesse público (PAES DE PAULA, 2005). 
Posteriormente, o empreendedorismo no setor público teve como propulsor os governos neoliberais (PAES DE PAULA, 2005; SECCHI, 2009; DIEFENBACH, 2011). Foi por meio desse pensamento que a questão do governo empreendedor se intensificou nos Estados Unidos com a obra Reiventando o Governo (OSBORNE; GAEBLER, 1994). Nessa obra, David Osborne e Ted Gaebler focam as ideias de eficiência e empreendedorismo, comprovando, segundo Paes de Paula (2005, p. 61), "[...] que o gerencialismo havia se deslocado do setor privado para o setor público". No Brasil, o empreendedorismo foi incorporado à Administração Pública pela via das reformas administrativas. Em âmbito nacional, foi constituído o Programa Nacional de Gestão Pública e Desburocratização (GesPública). No entanto, o mais conhecido e mais difundido modelo de gestão pública empreendedora foi o estabelecido em Minas Gerais. As três gerações do chamado Choque de Gestão trouxeram diversas mudanças para a gestão pública mineira, e é com base nessa notória experiência contemporânea que este artigo se desenvolve.

Portanto, nosso questionamento central consiste em saber quais são os elementos da prática social presentes no discurso de incorporação do empreendedorismo no setor público no estado de Minas Gerais. Dessa maneira, esta pesquisa tem como objetivo analisar os elementos da prática social presentes no discurso de incorporação do empreendedorismo no setor público na experiência recente do estado de Minas Gerais, ocasionada pelo Choque de Gestão. Para evitar ambiguidades, utilizaremos New Public Management para nos referirmos à reforma em nível mundial (PAES DE PAULA, 2005) e Reforma Gerencial ou Administração Pública Gerencial para nos referirmos à reforma no Brasil (BRESSER-PEREIRA, 1998; BRESSER-PEREIRA; SPINK, 2006).

Em termos operacionais, além desta introdução, apresentamos uma discussão sobre a incorporação do empreendedorismo no setor público, o neoliberalismo e a New Public Management. Em seguida, discutimos a metodologia de pesquisa com ênfase para o enfoque teóricometodológico da ADC. Nos resultados, destacamos os elementos da prática social presentes nos ciclos de gestão e no empreendedorismo no setor público de Minas Gerais e, nas considerações finais, debatemos as implicações, limitações e recomendações deste estudo.

\section{A INCORPORAÇÃO DO EMPREENDEDORISMO NO SE- TOR PÚBLICO}

A discussão sobre o empreendedorismo no setor público não é recente. Desde 1965, quando Elinor Ostrom desenvolveu seu trabalho denominado Public Entrepreneurship: a case study in ground water basin management, já havia debates sobre a possibilidade do empreendedorismo no contexto do setor público. As motivações neoliberais que influenciaram a obra de David Osborne e Ted Gaebler, denominada Reinventing Government: How the Entrepreneurial Spirit is Transforming the Public Sector e publicada originalmente em 1992, foram a base para a propagação e disseminação da tese de reinvenção de governos por meio do espírito empreendedor (FARAZMAND, 2012). Na visão de Osborne e Gaebler (1994, p. 13-14), "o tipo de governo que se desenvolveu durante a era industrial, com suas burocracias lentas e centralizadas, preocupado com normas e regulamentos, sujeito a cadeias de comando hierárquicas, deixou de funcionar bem" na era da globalização e da tecnologia da informação.

Historicamente, a concepção de empreendedorismo esteve arraigada a uma perspectiva de mercado capitalista, em que o empreendedor representava o objeto de manutenção e propagação do desenvolvimento econômico (COSTA; BARROS; CARVALHO, 2011). Dessa forma, “[...] apesar de existirem registros anteriores em outras áreas, há um consenso na literatura de que a palavra francesa para empreendedor - entrepreneur - foi introduzida no contexto econô- 
mico da criação e gestão de novos negócios principalmente por dois autores" (BITTAR; BASTOS; MOREIRA, 2014, p. 68): Richard Cantillon, em 1755, e Jean-Baptiste Say, em 1803 (FILION, 1999). Para Sadler (2000), o conceito de Cantillon buscou explicar a receptividade ao risco de comprar algo por um preço e vendê-lo em regime de incerteza. Jean Say, por sua vez, sustentou que o empreendedor seria capaz de alterar os recursos econômicos de uma área de baixa produtividade, transformando-a em uma área de produtividade e lucratividade elevadas e atuando, assim, como catalisador do desenvolvimento econômico (SADLER, 2000). Tanto na definição de Cantillon quanto na de Say, o empreendedor é considerado um agente tomador de risco (SADLER, 2000). Dessa forma, "[...] foi apenas no final do século XII e início do século XIII que o termo foi usado para se referir à pessoa que criava e conduzia projetos ou empreendimentos" (VIEIRA; MELATTI; RIBEIRO, 2011, p. 290).

Algum tempo depois, Schumpeter (1954) alinhou o conceito de empreendedorismo ao de inovação (SADLER, 2000). Na perspectiva de Schumpeter (1954), o empreendedor conduzia e criava novas combinações de produção por meio do processo de destruição criativa, atuando como "[...]o agente econômico que traz novos produtos para o mercado por meio de combinações mais eficientes dos fatores de produção ou pela aplicação prática de alguma invenção ou inovação tecnológica" (BITTAR; BASTOS; MOREIRA, 2014, p. 68). Nesse sentido, o ímpeto para o sistema econômico vem de homens de coragem, que arriscam para implementar, inovar, experimentar e expandir novas ideias (SCHUMPETER, 1954): o empreendedor ganha status de líder que possui visão de futuro (GOMES et al., 2012).

Escolas posteriores que buscaram compreender o comportamento dos empreendedores também não deixaram de sustentar uma epistemologia funcionalista do termo, vislumbrando um ganho com o empreendimento construído (VALADARES; EMMENDOERFER, 2013). Ainda é nessa perspectiva que se insere o pensamento de McClelland e Burnham (1976) ao evidenciarem que, no âmago do empreendedor, está a busca da autorrealização (achievement).

No que se refere ao âmbito público, autores como Roberts e King (1991), Osborne e Gaebler (1994), Diefenbach (2011) e Valadares e Emmendoerfer $(2012,2013)$ buscaram analisar o conceito de empreendedorismo associado à Administração Pública. Nas definições dos autores, é possível perceber que o pensamento neoliberal tem sido marcante na incorporação desse conceito.

Em recente pesquisa, Moraes, Valadares e Emmendoerfer (2013) evidenciaram que a incorporação do empreendedorismo no setor público é uma prática presente, principalmente, em países europeus. Em termos de trabalhos científicos, os autores mostraram que é na Europa e nos Estados Unidos que a literatura sobre empreendedorismo no setor público é mais ampla. Moraes, Valadares e Emmendoerfer (2013) demonstraram que existe uma lacuna no que concerne ao estudo da incorporação do empreendedorismo no setor público pela via interpretativa e crítica, pois a maioria das pesquisas tem se pautado em uma epistemologia funcionalista, não conferindo ênfase às implicações dessa incorporação para as organizações públicas. Os estudos que analisam a noção de empreendedorismo no setor público incorporam conceitos como inovação, proatividade, identificação de oportunidades, riscos e criação de valor sem uma análise reflexiva de como estes conceitos impactam a Administração Pública e suas relações com a sociedade e o mercado (VALADARES; EMMENDOERFER, 2013). Dessa forma, os resultados são definições difusas que não refletem uma teorização coerente para a Administração Pública.

Por isso, a incorporação do empreendedorismo no setor público é um fenômeno que demanda análises críticas. Apesar de os defensores da incorporação do empreendedorismo na Administração Pública argumentarem que tal fenômeno pode trazer benefícios sociais e sustentáveis para o setor e principalmente para a sociedade, deve-se considerar que o cerne desse pen- 
samento se encontra no próprio desenvolvimento do capitalismo, ou seja, no desenvolvimento econômico (ANDREWS; KOUZMIN, 1998; COSTA; BARROS; CARVALHO, 2011). Sobre empreendedorismo e capitalismo, Costa, Barros e Carvalho (2011) mostram que existe uma relação robusta entre a formação do capitalismo e a ascensão dos empreendedores como agentes de fomento do crescimento econômico e também do progresso industrial daquela época.

Com base nas críticas supracitadas, observamos que, assim como ocorreu com a New Public Management, o pensamento neoliberal tem sido a base norteadora para a criação de práticas empreendedoras na Administração Pública. Dessa maneira, cabe refletir se essa forma de incorporação do empreendedorismo pode trazer benefícios sociais e sustentáveis para a Administração Pública e principalmente para a sociedade (ANDREWS; KOUZMIN, 1998; COSTA; BARROS; CARVALHO, 2011).

\section{O NEOLIBERALISMO E A NEW PUBLIC MANAGEMENT}

A década de 1980 foi marcante para a Administração Pública mundial, pois abrigou o início de um processo de mudança na gestão de muitos países, a partir das reformas empreendidas no Reino Unido e nos Estados Unidos, estabelecendo as bases da New Public Management (PAES DE PAULA, 2005). O discurso neoliberal ganhou um sentido de reação ideológica contra os pensamentos intervencionistas do Estado. O neoliberalismo caracterizou-se pelo renascimento do pensamento liberal em um contexto de profunda luta contra o Welfare State (ANDREWS; KOUZMIN, 1998; PAES DE PAULA, 2005).

Esse discurso emergiu principalmente após a publicação, em 1944, de $O$ Caminho da Servidão, de Friedrich Hayek. Nessa obra, Hayek (1987) aponta a intervenção do Estado como possível caminho da servidão que destrói a capacidade competitiva do mercado e propicia o advento de governos totalitaristas. Notadamente, esse autor apresenta a postura de combate ao modelo do Welfare State (PAES DE PAULA, 2005). Esse movimento tomou ainda mais força com a publicação da obra Capitalismo e Liberdade, de Milton Friedman, que assegurava a liberdade dos indivíduos por meio da liberdade econômica (FRIEDMAN, 1977). Com isso, surgiu também um forte movimento voltado para o espírito empreendedor.

Em um contexto no qual diversos países estavam em choque (KLEIN, 2008), passando por crises, o discurso neoliberal tornou-se hegemônico e, por intermédio de vozes como Ronald Reagan e Margaret Thatcher, ganhou força, preparando o terreno para as reformas administrativas (ANDREWS; KOUZMIN, 1998; SPINK, 1998; ABRUCIO, 1998; KETTL, 2006). Assim, “[...] essas concepções jamais foram derrotadas numa grande batalha de idéias, nem foram rejeitadas nas eleições" (KLEIN, 2008, p. 536), e os governos "[...] se renderam às reformas neoliberais" (PAES DE PAULA, 2005, p. 78).

Essas reformas, segundo Spink (1998), Abrucio (1998) e Secchi (2009), tornaram-se prerrogativa em quase todo o mundo e basearam-se na reorganização da gestão pública, trazendo alicerces para a constituição da Administração Pública Gerencial e do Governo Empreendedor. Para essa corrente, a organização pública deve ser concebida, organizada, gerida e orientada para o mercado, de forma que, no setor público, deve-se utilizar conceitos da gestão privada tais como desempenho, redução de custo, eficiência, produtividade e visão focada nos clientes (HOOD, 1991).

De acordo com Paes de Paula (2005, p. 82), a New Public Management não deixa de ser um instrumento de promoção dos "[...] interesses de carreira de uma elite gerencial constituída por altos executivos, consultores que atuam no setor público e escolas de negócios voltadas para o treinamento e desenvolvimento de gestores". Segundo a autora, os críticos ainda mencionam que o modelo centraliza o poder de decisão na cúpula gerencial, já que a formulação das políticas públicas é de responsabilidade exclusiva dos ministérios e das secretarias do Estado, ou seja, con- 
tribui para a formação de ilhas de conhecimento dentro da Administração Pública, promovendo o insulamento burocrático desta (DINIZ, 1997). Outro fator limitante é a aposta de que a New Public Management oferece técnicas mais adequadas para a superação da ineficiência administrativa e da má utilização de recursos. Além disso, há o fato de que a administração dos setores público e privado apresenta características que as distanciam em termos de gestão, principalmente no que tange aos aspectos sociopolíticos (PAES DE PAULA, 2005).

Vogel (2012), no contexto alemão, revela diversos conflitos entre os modelos gerenciais e burocráticos de gestão do setor público, existindo aqueles que defendem a transferência das práticas gerenciais e aqueles que são contra. A conclusão central do autor é de que a legitimidade e a superioridade do modelo gerencial são um produto do discurso. Van Helden e Jansen (2003) entendem que as mudanças no governo holandês em decorrência da New Public Management foram apenas superficiais e com impacto limitado. Já para Perren e Jennings (2005) os discursos governamentais sobre empreendedorismo reproduzem as crenças presentes no empreendedorismo no setor privado.

Para Diefenbach (2009), é preciso refletir sobre as implicações da New Public Management para as organizações públicas, pois, embora à primeira vista suas ideias sejam convincentes, podem gerar desdobramentos bastante questionáveis. O estabelecimento de uma lógica de mercado para as organizações públicas, por exemplo, contribui para a mercantilização dos serviços públicos. Diefenbach (2009) destaca diversos impactos negativos da New Public Management para as organizações do setor público e também para os indivíduos: inconsistências do conceito; centralização; foco na mudança como capacidade organizacional; padronização e formalização da gestão; e vigia e controle dos funcionários ao mesmo tempo em que se exige deles proatividade e outras atitudes do business-like.

Em relação a essas críticas, observamos que a New Public Management vai ao encontro das ideias de criar um novo valor do serviço público baseado na quantificação e monetarização, de modo que o ethos do serviço público e seu compromisso com a imparcialidade, igualdade social, integridade e equidade vão sendo deixados de lado (KLEIN, 2008; DENHARDT; DENHARDT, 2000).

Outra questão problemática é o que se denomina orientação para o cliente. Dienfenbach (2009) adverte que essa prática pode tornar o cidadão um coadjuvante nas decisões públicas, ou seja, um indivíduo que simplesmente exige a pronta entrega de um serviço para suas próprias necessidades. Nesse caso, existe uma inversão e subversão de importantes valores democráticos, de forma que estabelecer uma relação de empresa-cliente no setor público não é concebível, pois a tentativa de orientar o setor público pela lógica do mercado contribui para a criação de mercados e universos paralelos de negociação. Ainda nesse escopo, conforme Denhardt e Denhardt (2000), o discurso da New Public Management foca essencialmente a ideia de cidadãos como customers.

Além dos pontos críticos listados anteriormente, a corrente dos Estudos Organizacionais Críticos também apresenta fatores limitantes da aplicabilidade do modelo gerencial nas organizações públicas. Os Estudos Organizacionais Críticos destacam-se no conjunto por prover um contraponto crítico para os estudos mainstream no campo do management, além de serem suficientemente amplos para servir como fonte de reflexão para debates epistemológicos, abordando noções de racionalidade e progresso, tecnocracia, autonomia, controle, poder e ideologia.

A principal crítica deste movimento reside no fato de que as práticas gerenciais e suas racionalidades têm sido adotadas nas organizações públicas como mecanismo de resolução de todos os problemas. Essa crença, segundo Wood Jr. e Paula (2002), reside principalmente na difusão dos gurus do management e dos modismos gerenciais. Para estes autores, as ferramentas de gestão aplicadas às organizações privadas nem sempre são eficientes e, quando são transpostas para o setor público, apresentam limites importantes na sua aplicação, além de se materializarem como ferramentas ideológicas de dominação. 


\section{METODOLOGIA DE PESQUISA}

\subsection{Delineamento da pesquisa}

Este estudo qualitativo consiste em uma análise longitudinal por usar dados que descrevem os ciclos da gestão pública em Minas Gerais ao longo do tempo, mais precisamente em um período de dez anos. A coleta de dados foi elaborada a partir de materiais bibliográficos e documentais (DENZIN; LINCOLN, 2006) provenientes das seguintes fontes específicas: relatórios, atas, livros e leis (conforme Quadro 1).

\begin{tabular}{|c|c|c|c|}
\hline Documentos & Tipos & Órgão responsável & Ano \\
\hline $\begin{array}{l}\text { Plano de Desenvolvimento Integrado (PMID 2000-2003): } \\
\text { Uma Estratégia para o Desenvolvimento Sustentável }\end{array}$ & Relatório & Governo de Minas Gerais & 1999 \\
\hline Minas Gerais do Século XXI & Relatório & $\begin{array}{c}\text { Banco de Desenvolvimento } \\
\text { de Minas Gerais (BDMG) }\end{array}$ & 2002 \\
\hline Mensagem do Governador n. 0343 & Proposição & $\begin{array}{l}\text { Assembleia Legislativa de } \\
\text { Minas Gerais (ALMG) }\end{array}$ & 2002 \\
\hline Parecer Final do Projeto de Resolução n. 02472 & Ata & $\begin{array}{l}\text { Assembleia Legislativa de } \\
\text { Minas Gerais (ALMG) }\end{array}$ & 2002 \\
\hline Plano de Desenvolvimento Integrado (PMDI 2003-2020) & Relatório & Governo de Minas Gerais & 2003 \\
\hline $\begin{array}{c}\text { O Choque de Gestão em Minas Gerais: Políticas da } \\
\text { Gestão Pública Para o Desenvolvimento }\end{array}$ & Livro & Governo de Minas Gerais & 2006 \\
\hline Mensagem do Governador n. 0992 & Proposição & $\begin{array}{l}\text { Assembleia Legislativa de } \\
\text { Minas Gerais (ALMG) }\end{array}$ & 2006 \\
\hline $\begin{array}{l}\text { Votação, em 10 turno, do Projeto de Resolução n.o } \\
3768\end{array}$ & Ata & $\begin{array}{l}\text { Assembleia Legislativa de } \\
\text { Minas Gerais (ALMG) }\end{array}$ & 2006 \\
\hline Lei Delegada n.ㅇ 112 (Estado Para Resultados) & Lei & $\begin{array}{l}\text { Assembleia Legislativa de } \\
\text { Minas Gerais (ALMG) }\end{array}$ & 2007 \\
\hline Lei Delegada n.o 174 (Empreendedor Público) & Lei & $\begin{array}{l}\text { Assembleia Legislativa de } \\
\text { Minas Gerais (ALMG) }\end{array}$ & 2007 \\
\hline Lei Delegada n.o 175 & Lei & $\begin{array}{l}\text { Assembleia Legislativa de } \\
\text { Minas Gerais (ALMG) }\end{array}$ & 2007 \\
\hline $\begin{array}{l}\text { Plano de Desenvolvimento Integrado (PMDI 2007- } \\
\text { 2023) }\end{array}$ & Relatório & Governo de Minas Gerais & 2007 \\
\hline Mensagem do Governador n.o 552 & Proposição & $\begin{array}{l}\text { Assembleia Legislativa de } \\
\text { Minas Gerais (ALMG) }\end{array}$ & 2010 \\
\hline Votação do Projeto de Lei n. 4917 & Ata & $\begin{array}{l}\text { Assembleia Legislativa de } \\
\text { Minas Gerais (ALMG) }\end{array}$ & 2010 \\
\hline $\begin{array}{l}\text { Votação, em 20 turno, do Projeto de Resolução n.o } \\
4999 / 2010\end{array}$ & Ata & $\begin{array}{l}\text { Assembleia Legislativa de } \\
\text { Minas Gerais (ALMG) }\end{array}$ & 2010 \\
\hline Agenda de Melhorias: Empreendedor Público & Relatório & Governo de Minas Gerais & 2010 \\
\hline $\begin{array}{c}\text { Agenda de Melhorias: Relatório Benchmark para as } \\
\text { Iniciativas EP, EPP e PD Minas }\end{array}$ & Relatório & Governo de Minas Gerais & 2010 \\
\hline $\begin{array}{l}\text { Empreendedores Públicos no Governo de Minas Ge- } \\
\text { rais: Registro de uma Experiência de Resultados }\end{array}$ & Livro & Governo de Minas Gerais & 2010 \\
\hline $\begin{array}{l}\text { Estado Para Resultados: Avanços no Monitoramento e } \\
\text { Avaliação da Gestão Pública em Minas Gerais }\end{array}$ & Livro & Governo de Minas Gerais & 2010 \\
\hline $\begin{array}{l}\text { Plano de Desenvolvimento Integrado (PMDI 2011- } \\
\text { 2030): Gestão para Cidadania }\end{array}$ & Relatório & Governo de Minas Gerais & 2011 \\
\hline Lei Delegada n.o 180 & Lei & $\begin{array}{l}\text { Assembleia Legislativa de } \\
\text { Minas Gerais (ALMG) }\end{array}$ & 2011 \\
\hline Lei Delegada n.o 182 & Lei & $\begin{array}{l}\text { Assembleia Legislativa de } \\
\text { Minas Gerais (ALMG) }\end{array}$ & 2011 \\
\hline
\end{tabular}

Quadro 1 - Lista de Documentos Analisados.

Fonte: elaborado pelos autores. 
Destacamos que os autores dos documentos são aqueles envolvidos na concepção da reforma administrativa do Estado de Minas Gerais e estão diretamente ligados à construção e organização dos documentos analisados, ou seja, refletem a visão e o interesse da administração direta do Estado de Minas Gerais.

\subsection{Análise de Discurso Crítica (ADC)}

Como enfoque teórico-metodológico, utilizamos a ADC com destaque para as contribuições de Norman Fairclough (FAIRCLOUGH, 2001). Em termos epistemológicos, a ADC rejeita a ideia de uma ciência neutra (ALVES; GOMES; SOUZA, 2006). Nesse sentido, Melo (2009, p. 13) coloca que "Fairclough assume que a neutralidade, diante das estruturas sociais, numa pesquisa, torna o pesquisador cúmplice de tais estruturas".

Conforme Melo (2009, p. 3), para Fairclough (2001) o discurso é uma prática social “[...] reprodutora e transformadora de realidades sociais" e, assim, "a língua é uma atividade dialética que molda a sociedade e é moldada por ela". Para Fairclough (2001, p. 91), "o discurso [é] um modo de ação, uma forma em que as pessoas podem agir sobre o mundo e especialmente sobre os outros, como também um modo de representação". Segundo Alves, Gomes e Souza (2006), uma análise de discurso é sempre uma análise crítica, pois diz respeito à busca por revelar o poder, a ideologia e a hegemonia que são subjacentes aos processos de construção da realidade social, de modo que as palavras poder, dominação, hegemonia, ideologia, classe, discriminação, interesse, reprodução, instituição, estrutura social, ordem social e prática social são usuais na ADC.

Para Fairclough (2001), o discurso é um conjunto de textos e de práticas de produção discursivas e sociais. Logo, essa perspectiva possui "foco tanto nos processos e nas práticas sociais como no papel do discurso na produção e/ou reprodução de relações assimétricas de poder" (RODRIGUES; DELLAGNELO, 2013, p. 629). O discurso como prática social é reprodutor e transformador da realidade - socialmente constituído, bem como socialmente condicionado (FAIRCLOUGH, 2001).

Segundo Resende e Ramalho (2013), a ADC é crítica por se orientar pela busca dos modos pelos quais o discurso se relaciona com a prática social, atentando especialmente aos seus efeitos nas lutas hegemônicas. A ADC, nesse sentido, é pautada nas práticas sociais que revelam os métodos de manutenção e abuso de poder, sendo função do analista "[...] aumentar a consciência de que a linguagem contribui para a dominação de uma pessoa sobre a outra, tendo em vista tal consciência como primeiro passo para a emancipação" (MELO, 2009, p. 9).

Nessa direção, Fairclough (2001) propõe um modelo tridimensional de análise: texto, prática discursiva e prática social (conforme Quadro 2).

\begin{tabular}{|c|c|c|}
\hline Texto & Prática Discursiva & Prática Social \\
\hline & Produção & Ideologia \\
Vocabulário & Distribuição & Sentidos \\
Gramática & Consumo & Pressuposições \\
Coesão & Contexto & Metáforas \\
Estrutura textual & Força & Hegemonia \\
& Coerência & Orientações econômicas, \\
& Intertextualidade & políticas, culturais e ideológicas \\
\hline
\end{tabular}

Quadro 2 - Categorias analíticas propostas no modelo tridimensional.

Fonte: Resende e Ramalho (2013, p. 29).

O presente trabalho centra-se, em especial, em duas categorias do discurso como prática social: ideologia e hegemonia. 


\subsubsection{O discurso como prática social}

Fairclough (2001, p. 123) considera a ideologia como "uma concepção do mundo que está implicitamente manifesta na arte, no direito, na atividade econômica e nas manifestações da vida individual e coletiva"; trata-se, conforme Thompson (2009), de uma forma de poder. Os modos gerais de operação da ideologia são a legitimação, a dissimulação, a unificação, a fragmentação e a reificação (RESENDE; RAMALHO, 2013). Esses modos de operação constituem pressupostos básicos de análise para esta pesquisa, pois, alinhados com as lutas hegemônicas, são elementos importantes para a análise do discurso sobre empreendedorismo na Administração Pública na experiência analisada.

Fairclough (2001) trabalha com a concepção de hegemonia gramsciana. Nesse ínterim, hegemonia "[...] é a liderança nos campos: econômico, político, cultural e ideológico de uma sociedade. Essas lideranças são constituídas através de alianças com outras forças, mas detêm um poder parcial e temporário, com um equilíbrio instável" (SOUZA, 2012, p. 12). Dentro da concepção de Gramsci (2000), a hegemonia relaciona-se com a classe dominante e a forma desta de "[...] produzir e organizar o consenso e a direção política, intelectual e moral" (ACANDA, 2006, p. 178). Dessa maneira, "a prática discursiva, a produção, a distribuição e o consumo de textos são uma faceta de luta hegemônica que contribui para a reprodução ou transformação da ordem de discurso existente e das relações sociais e assimétricas constitutivas" (SOUZA, 2012, p. 12).

O conceito de hegemonia gramsciana relaciona-se, portanto, diretamente com o de intelectuais orgânicos como sujeitos que "[...] assumem funções essenciais à manutenção da direção hegemônica de um bloco histórico" (VASCONCELOS; SILVA; SCHMALLER, 2013, p. 85). Assim, são os praticantes e teóricos que defendem e justificam o modelo, seja a Reforma do Estado, seja o Choque de Gestão em estudo.

Diante dessas considerações sobre a coleta e análise dos dados, na seção seguinte, realizamos a análise dos elementos ideológicos e hegemônicos presentes no discurso do empreendedorismo incorporado ao setor público de Minas Gerais.

\section{OS CICLOS DE GESTÃO E O DISCURSO DO EMPREEN- DEDORISMO EM MINAS GERAIS}

A história recente da Administração Pública no estado de Minas Gerais é formada por três ciclos da gestão pública a partir de 2003. Com base nos dados analisados, nota-se que, nesse período, houve uma busca acelerada por resultados via a implementação da Administração Pública Gerencial nos moldes da New Public Management e do discurso do neoliberalismo. De acordo com Anastasia (2006, p. 13, grifo nosso), "o ideal de um aparato público funcionando com plena eficiência, apresentando resultados positivos e, por consequência, sendo reconhecido como adequado pela respectiva comunidade é a meta de todo administrador bem intencionado". Partindo dessa premissa, segundo o autor, as transformações enfrentadas pelo estado mineiro naquela época contribuiriam para a superação de dificuldades fiscais e para alcançar os resultados de desenvolvimento traçados no Plano de Governo 2003/2006.

Em cada fase, podemos destacar que o texto (primeira categoria do modelo de Fairclough) foi algo marcante para a legitimação da reforma administrativa mineira. Nesse sentido, os textos foram produzidos, distribuídos e consumidos tanto em âmbito institucional (VILHENA et al., 2006; GUIMARÃES; PORDEUS; CAMPOS, 2010; GUIMARÃES; BERNARDI, 2010) quanto em âmbito acadêmico (BERNARDI; GUIMARÃES, 2008; CAMPOS; BERNARDI, 2008; BERNARDI; CAM- 
POS, 2010; LOPES; CAMPOS, 2010) e também pela sociedade em forma de programas de rádio, televisão e reportagens na mídia impressa. Esses textos estão relacionados, conforme o modelo de Fairclough (2001), às práticas discursivas e sociais.

O primeiro ciclo (2003-2006) de gestão em Minas (Choque de Gestão), segundo Vilhena et al. (2006, p. 21), configurou-se como “[...] um conjunto integrado de políticas de gestão pública orientado para o desenvolvimento". O Choque de Gestão definiu-se como processo de reengenharia realizado no âmbito executivo de Minas Gerais, que teve como uma de suas características a lógica do planejamento estratégico da ação estatal voltada para resultados. A partir do Choque de Gestão mineiro, o planejamento do referido Estado-membro desenvolveu-se por meio da abordagem do Duplo Planejamento (metodologia que alinha estratégias de curto, médio e longo prazo). No período de 2003-2006, Porto e Silveira (2010) observam que foram empreendidos, além do ajuste fiscal realizado em modelos de gestão desse tipo, três esforços de alinhamento principais:

[...] das organizações, por meio dos Acordos de Resultados e de iniciativas de implementações de Organizações da Sociedade Civil de Interesse Público (Oscips) e de parcerias público-privadas; das pessoas, através da avaliação de desempenho, da reestruturação de carreiras e do desenvolvimento de competências; e dos principais sistemas administrativos (PORTO; SILVEIRA, 2010, p. 23).

Já o segundo ciclo (2007-2010), denominado Programa Estado para Resultados (EpR), correspondeu à segunda geração do Choque de Gestão mineiro. Nesta, foi definida a orientação do governo baseada em resultados como característica marcante da cultura do ambiente institucional do setor público de Minas Gerais (GUIMARÃES; PORDEUS; CAMPOS, 2010).

Destacamos, então, novamente a ideologia e hegemonia da cultura do gerencialismo presente no Programa Estado para Resultados quando este se orienta essencialmente pelos resultados. Observamos, ainda, a tentativa, sempre presente nesse processo, de reinventar o governo e legitimá-lo por meio da eficiência, e não da participação democrática. Raadschelders (2012) esclarece que a obra Reinventando o Governo se tornou popular não somente pela importância enquanto arcabouço teórico contextualizado ao setor público, mas também pelos raios da onda neoliberal que influenciou a gestão pública mundial e trouxe para o centro desta os instrumentos de gestão empresarial e uma racionalização instrumentalizada para os gestores públicos (ANDREWS; KOUZMIN, 1998; KETTL, 2006; KLEIN, 2008; SECCHI, 2009; DIEFENBACH, 2011).

Segundo Porto e Silveira (2010), o aprendizado e os bons resultados adquiridos com a implementação do Choque de Gestão (primeiro ciclo) forneceram estímulo para que o governo mineiro buscasse uma atualização de seu choque, inovando para alcançar novos patamares gerenciais para a Administração Pública do Estado. Além disso, foi realizada uma revisão do Plano Mineiro de Desenvolvimento Integrado (PMDI), “[...] no qual se propôs um aprofundamento na estratégia de intervenção em curso, bem como uma transformação do modo de gestão das organizações públicas que deveriam se nortear por resultados em vez de priorizar a estrutura organizacional" (GUIMARÃES; BERNARDI, 2010, p. 17). Dessa forma, foi criado o Programa Estado para Resultados (EpR) por meio do artigo 8 da Lei Delegada n. 112, de 25 de janeiro de 2007 (MINAS GERAIS, 2007a).

Para atualizar o PMDI para o horizonte de 2007-2023 (MINAS GERAIS, 2007b), partiu-se de um alinhamento conceitual das metodologias a serem utilizadas nesse novo projeto e de uma avaliação estratégica do período de 2003-2006. O trabalho desenvolvido na gestão anterior (20032006), acrescentado ao aprofundamento de análises retrospectiva e prospectiva sobre Minas Gerais, serviu de base para que a atuação do governo de Minas Gerais pudesse ser organizada em Áreas de Resultados, assegurando, assim, o foco na produção e entrega de resultados e benefícios para a sociedade. $\mathrm{O}$ EpR propiciou melhorias ou inovações à gestão pública mineira relacionadas à 
criação e operação do Programa Estado para Resultados, consolidação de comitês de resultados, intensificação e aprimoramento da sistemática de gerenciamento, monitoramento e disseminação dos Acordos de Resultados e instituição dos empreendedores públicos (MINAS GERAIS, 2007b).

Nesse ínterim, o discurso hegemônico entende que esse modelo consegue melhores resultados para a sociedade; no entanto, tal modelo se pauta por uma lógica de mercado (eficiência, desempenho e resultados) que nem sempre vai ao encontro do interesse público. Ramos (1981) já alertava para as implicações da invasão de toda a vida humana associada, o que inclui a política, pelo enclave econômico - ao ser colonizado pela lógica do mercado, a política, negócio tipicamente humano em sentido amplo, torna-se mercantilizada e orientada por uma racionalidade estratégica (HABERMAS, 1987). Nesse sentido, é importante destacar que "[...] a colocação inapropriada de conceitos impregna a literatura contemporânea sobre tópicos e problemas organizacionais e, em resultado a cidadela do conhecimento organizacional de nossos dias é semelhante a uma torre de Babel" (RAMOS, 1981, p. 81). O motivo para esse acontecimento, segundo o autor, é a linguagem deformadora originária da hegemonia dos critérios ou do enclave econômico sobre o tecido social.

Segundo Guimarães e Amorim (2013), a linguagem liberal é hegemônica nas democracias contemporâneas: é "a razão liberal que define as regras e estabelece as relações de sentido entre os conceitos" (AMORIM, 2013, p. 14). Essa linguagem distorce conceitos centrais à construção da opinião pública, da democracia e da liberdade. Exemplo disso é o fato de a New Public Management apresentar os cidadãos como customers e não como citizens (DENHARDT; DENHARDT, 2000).

O terceiro ciclo (2011-2014) de gestão em Minas Gerais, por sua vez, é marcado pela implementação do Escritório de Prioridades Estratégicas no ano de 2011. Segundo seus idealizadores, esse novo modelo de gestão visa implementar uma gestão para a cidadania, em que as políticas públicas seriam construídas focando o cidadão (VILHENA, 2012). O Escritório de Prioridades é um órgão autônomo de governo, ligado diretamente ao governador, que objetiva contribuir para a definição das prioridades estratégicas do Governo mineiro, assumindo o status de Secretaria de Estado, o que implica a função de colaborador junto aos órgãos da Administração Pública e do Poder Executivo. Estrutura-se em três núcleos: a) Avaliação, Análise e Informação (subsidia as decisões estratégicas governamentais por meio da disponibilização de informações, bem como a promoção de aprendizagem organizacional); b) Entrega e Empreendedores Públicos (papel de apoio na consecução das prioridades estratégicas); e c) Sistemas e Gestão (criação e gestão de soluções para facilitar a consolidação e disponibilização de bases de dados).

Consequentemente, a noção de empreendedorismo foi implementada na gestão pública de Minas Gerais por meio da instituição de um cargo denominado Empreendedor Público. Observamos que esse cargo foi concebido mediante um contexto em que o governo promoveu o desenvolvimento de um modelo de gestão que focava a entrega de resultados. Nesse sentido, o governo mineiro, no seu segundo ciclo de gestão, tomou a decisão de que um dos focos de atuação do Programa Estado para Resultados seria a gestão de empreendedores públicos. Estes empreendedores, segundo Guimarães e Bernardi (2010), seriam selecionados, alocados e teriam o status de uma força-tarefa aplicada a áreas estratégicas do Governo. Dessa forma, foi criado um cargo de provimento em comissão de recrutamento amplo de empreendedor público, com o objetivo de contribuir para alcançar os resultados estabelecidos na estratégia de Governo.

No que concerne à origem e criação desse cargo, Bernardi (2010, p. 38, grifo nosso) destaca que, a despeito dos obstáculos e das barreiras à inovação e ao espírito empreendedor no serviço público, "o governo de Minas Gerais, a partir de 2003, vem adotando um modelo de planejamento e de gestão estratégica, criando um terreno fértil para a atuação de profissionais empreendedores". Assim, segundo a autora, "a criação do cargo de empreendedor público está 
atrelada à reforma que sofreu a Administração Pública no início de 2007" (BERNARDI, 2010, p. 1). A construção desse cargo, segundo Guimarães e Bernardi (2010), foi baseada em seis competências para a composição de um perfil ideal, das quais três seriam essenciais (orientação para resultados, proatividade e compreensão da dinâmica institucional) e três seriam desejáveis (gerenciamento de projetos, inovação e liderança).

Observamos, diante disso, que as características do cargo de empreendedor público são as exigidas pelo mercado: proatividade, liderança e orientação para resultados. Percebemos que esse discurso indica que o sucesso do empreendedor depende de competências cultuadas pelo management e pelos gurus da administração. Nesse sentido, não há indicação da importância do bem público ou da capacidade de pensar sobre o interesse público ou comum (silêncios do discurso). Logo, a racionalidade em termos weberianos é com relação a fins - avalia os custos e benefícios de suas ações (TENÓRIO, 2008).

Até o momento, apresentamos de forma geral a contextualização histórica e alguns elementos ideológicos e hegemônicos da experiência analisada. Agora, argumentamos que pela perspectiva da ADC é possível observar que a prática social do governo mineiro está atrelada ao modelo hegemônico do neoliberalismo e ao enclave do mercado (like a business).

Como visto em seções anteriores, os idealizadores da reforma administrativa mineira destacaram que esta foi notável ao estabelecer medidas de rápido impacto para modificar, de vez, o padrão de comportamento da Administração Pública estadual, imprimindo-lhe um ritmo consentâneo com a contemporaneidade própria de uma gestão efetiva e eficaz presente no setor privado. O cargo de empreendedor foi uma das principais inovações gerenciais do governo mineiro nesse período. É necessário destacar que, segundo seus idealizadores, tais inovações gerenciais trouxeram maior agilidade, eficiência e eficácia para o governo mineiro.

No entanto, além de contribuir para maior centralização do poder por parte do executivo e responder aos interesses deste, existiu baixa participação social na gestão pública mineira durante o período analisado. Isso pode ser comprovado pelas diversas leis delegadas que se tornaram base do governo mineiro (MINAS GERAIS, 2007a; MINAS GERAIS, 2007). Segundo Melo (2008), a lei delegada ocorre mediante entrega do poder de elaborar leis do Legislativo para o Executivo. A esse respeito, Carvalho Júnior (2008) observa que as leis delegadas podem ser entendidas como forma atípica de atuação do Poder Executivo, ou seja, do governo como elaborador de leis, uma vez que o papel de elaborar leis é do Legislativo. Ora, se o próprio executivo elabora as leis, isso gera um descompasso/desequilíbrio nos três poderes do Estado e, em sua última instância, inibe a participação social.

Dessa forma, as implicações da incorporação do empreendedorismo no setor público mineiro geraram desdobramentos contraditórios. No entanto, apesar de existirem críticas internas, ou seja, críticas do Legislativo ao Executivo representado pelos partidos de oposição em discursos pronunciados na Assembleia Legislativa de Minas Gerais (ALMG) (VALADARES; EMMENDOERFER, 2013), o modelo de gestão baseado na Nova Administração Pública mineira mantém-se "firme" e a "todo vapor" e tem sido utilizado como base para a adoção em outros estados (IMASATO; MARTINS; PIERANTI, 2010), apoiando-se no discurso de que o cargo de empreendedor público tem alavancado os resultados do Estado mineiro (BERNARDI, 2010; GUIMARÃES; BERNARDI, 2010; LOPES; CAMPOS, 2010). Contudo, a utilização de leis delegadas e cargos comissionados para criar a noção de empreendedorismo em sua Administração Pública reforça os desafios de se construir um modelo que não entre em conflito com pressupostos democráticos.

Consequentemente, a Administração Pública mineira passou a ser permeada por elementos da lógica do mercado (like a business) que a transformaram em um ambiente de concor- 
rência e busca por resultados, acarretando problemas típicos do modus operandi capitalista. Nesse sentido, por meio do choque, difundiu-se a cultura do management, naturalizando os valores e as práticas do mundo dos negócios e legitimando discursivamente esse modelo como opção viável e necessária (os ditos), ao mesmo tempo em que se apagaram as inconsistências, limitações e mazelas do processo (os silêncios). Como materialização dessa realidade, observamos os trabalhos de Queiroz e Ckagnazaroff (2010), Paiva e Couto (2008) e Peci et al. (2008).

Queiroz e Ckagnazaroff (2010) destacaram que as mudanças proporcionadas pelo Choque de Gestão foram estritamente gerenciais e que houve limitações no que se refere às dimensões de ordem humana, cultural e política da mudança. Assim,

[...] o modelo de gestão desenvolvido no estado de Minas Gerais foi inovador em relação aos seguintes aspectos: estratégico, estrutural, tecnológico e de controle. Nas demais dimensões apresentadas - a humana, a cultural e a política, o CG, embora tenha provocado alguns efeitos em direção às mesmas, não considerou, em sua concepção, as três perspectivas como finalidades prioritárias da mudança pretendida. Além disso, pôdese concluir também que o choque representou uma mudança de cunho estritamente gerencial (QUEIROZ; CKAGNAZAROFF, 2010, p. 702-703, grifo nosso).

Paiva e Couto (2008), por sua vez, demonstraram o impacto na qualidade de vida e o estresse gerado no período pós-Choque de Gestão mineira. Já Peci et al. (2008) mostraram que a orientação para resultados do Choque de Gestão foi incorporada até mesmo no discurso das Oscips. Além disso, existe uma centralização no Estado, evidenciando até mesmo uma disfunção da implementação do modelo gerencial:

O Estado é responsável por convocar boa parte das parcerias, por conceber novos papéis cruciais à gestão das parcerias (como supervisor e técnico) e por adotar novos mecanismos de fiscalização de resultados. A falta de atuação dos conselhos de representação da sociedade civil nas parcerias público-privadas faz com que os espaços vazios estejam preenchidos pelas estruturas burocráticas, fonte anterior de crítica. Mais uma vez encontramos uma orientação de cima para baixo na reforma, com forte papel indutor dos técnicos do governo, como evidenciado em análises históricas das reformas brasileiras de gestão pública (PECl et al., 2008, p. 1159).

Notamos, assim, que as práticas sociais se materializaram em diversos momentos da gestão e organização do Estado mineiro, o que refletiu tanto nos processos de democratização quanto na qualidade de vida dos servidores públicos. Dentre os discursos possíveis, um dos silenciados é o de que o Choque de Gestão contribui para que os problemas típicos do modus operandi do mercado empresarial estivessem presentes no setor público.

\section{CONSIDERAÇÕES FINAIS}

Com base no estudo realizado, podemos observar diversos elementos da prática social (ideologia, hegemonia, orientações etc.) presentes no discurso de incorporação do empreendedorismo no setor público na experiência recente do estado de Minas Gerais com o Choque de Gestão. Como visto, a base sustentadora para esse discurso é o neoliberalismo e a cultura do management, que insere no setor público a lógica do mercado, transformando o cidadão em cliente. Assim, ressurge o problema da incompatibilidade dessa lógica com o interesse público.

Destacamos, ainda, como elemento ideológico a metáfora do Choque de Gestão. Por meio dessa metáfora, os idealizadores do choque indicam, discursivamente, que querem animar o Estado, proporcionando agilidade, eficiência e resultados. Klein (2008) mostra que a Doutrina do 
choque foi utilizada para implementar modelos neoliberais, isto é, quando em período de choque e confusão dos cidadãos (como um desastre natural ou uma crise econômica), o Estado realizava suas reformas. Nesse sentido, por intermédio do choque é que diversas medidas neoliberais foram implementadas com sucesso (KLEIN, 2008). Dessa forma, o choque é uma metáfora que revela um modo de representar a realidade (RESENDE; RAMALHO, 2013) - que se refere às reformas neoliberais como viáveis e necessárias em detrimento do silêncio sobre suas consequências e limitações.

Ao adentrar as organizações públicas, a lógica capitalista (sistema político-econômico e social hegemônico) transforma-as em um ambiente de concorrência e busca por resultados, acarretando problemas próprios do pensamento capitalista para o centro da Administração Pública. Como afirma Ramos (1981), a lógica do mercado gera comportamentos de busca pelo meIhor desempenho. Esse comportamento se baseia na racionalidade como cálculo utilitário das consequências (como as qualidades essenciais apresentadas para o empreendedor público) e é desprovido de conteúdo ético (RAMOS, 1981), isto é, de reflexões que levem em conta o interesse público e o bem comum (TENÓRIO, 2008).

É nesse sentido que reside a crítica ao discurso do empreendedorismo no setor público via New Public Management. Para legitima-la, os governos difundem a cultura do management no ambiente público a fim de sustentar suas próprias ideologias. Isso reflete uma postura de controle e manutenção de poder contrastante com uma cultura democrática e cidadã.

Diante disso, este artigo questiona esses caminhos e ressalta a importância dos processos de democratização pautados na cidadania, na participação e na deliberação. É na formação da cidadania (por meio da participação e da deliberação) que reside o potencial de emancipação social das ideologias e lutas hegemônicas neoliberais. A esse respeito, destacamos as iniciativas da sociedade na busca por uma gestão pública mais participativa e deliberativa e que alcance as necessidades sociais. Nessa perspectiva, assumimos como estratégia social para a emancipação da ideologia neoliberal um paradigma que seja verdadeiramente sociocêntrico (KEINERT, 2007) e uma gestão pública societal (PAES DE PAULA, 2005), em que a forma de gestão seja social (TENÓRIO, 2008). Ou seja, que as relações entre sociedade, mercado e Estado sejam pautadas em espaços e esferas públicas em que as pessoas possam dialogar e exercer poder comunicativo (HABERMAS, 1987, 2011). Tal estratégia se opõe, assim, ao modelo baseado na lógica do mercado e em seus discursos de desempenho, empreendedorismo e redução de custos.

No caso de Minas Gerais, é preciso que a gestão pública passe a englobar os problemas sociais, reconceituando a ideia de desenvolvimento pela incorporação de um modelo mais participativo e deliberativo de gestão ou, ainda, caminhando para uma ressignificação do empreendedorismo no setor público de forma mais reflexiva (VALADARES; SOUZA; VILAS BOAS, 2015). Um governo democrático não pode se manter apenas nas suas dimensões econômico-financeira e institucional-administrativa; é preciso focar os problemas públicos e os direitos cidadãos, já que "[...] o equilíbrio entre as dimensões é indispensável para a consolidação de uma gestão pública democrática" (PAES DE PAULA, 2005, p. 22). Não se faz uma gestão participativa perpetuando uma visão na qual o Estado tem maior poder sobre o cidadão, como vem sendo proclamado no terceiro ciclo de gestão, denominado Gestão para Cidadania, em Minas Gerais, nem tampouco pautado em uma lógica utilitária do mercado. A política é um fenômeno humano que precisa de ação, e não de um comportamento pautado no desempenho (RAMOS, 1981; ARENDT, 2010).

As reformas devem então, ser processos abertos à participação em locais públicos e à deliberação em esferas públicas, de modo que possam ser legitimadas pela vontade pública. A atuação da sociedade civil deve ser priorizada em detrimento da colonização pela lógica do mercado e do poder do Estado (HABERMAS, 2011). Nesse sentido, a cidadania constitui um elemento 
para o controle social e para a emancipação social no setor público, pois reflete "[...] a ação política deliberativa onde o indivíduo deve participar de um procedimento democrático, decidindo seu destino social como pessoa humana, quer como eleitor, trabalhador ou consumidor" (TENÓRIO et al., 2008, p. 15).

Voltando a questão do empreendedorismo, Box (1999) alerta que as demandas para o setor público tornar-se eficiente foram intensificadas e passaram a incorporar conceitos do setor privado, como o empreendedorismo, a privatização e a ideia de tratar o cidadão como um cliente. Segundo o autor, a dicotomia entre política e administração ameaça os valores fundamentais do setor público relacionados à democracia, ao interesse público e ao cidadão. Não se trata, obviamente, de não ser eficiente, mas de avançar também no aspecto democrático. Tendo isso em vista, Box et al. (2001) explicitam que o modelo de gestão do mercado impregnado no setor público afeta a dimensão substantiva da democracia no Estados Unidos, por exemplo. Para os autores, a New Public Management ameaça eliminar a democracia como um princípio orientador da gestão do setor público. Logo, esses debates precisam ser ampliados no que tange à realidade tanto nacional quanto do estado de Minas Gerais.

No que se refere à utilização da concepção de discurso de Fairclough (2001), destacamos que, "[...] como prática social, ele [o discurso] pode construir o mundo tanto de forma convencional assegurando a reprodução da sociedade, quanto de forma criativa buscando a transformação da sociedade" (CARRIERI; SOUZA; AGUIAR, 2014, p. 85). Consequentemente, a análise do discurso proporciona elementos de mudança, de modo que novas pesquisas poderão elucidar outros aspectos relacionados à difusão do empreendedorismo no setor público sob a ótica da ADC, ampliando as discussões sobre o tema e desvelando elementos opacos presentes nesses processos e em seus discursos. Mediante isso, é possível analisar os ditos, como também os silêncios, que constituem os recentes discursos na Administração Pública; afinal, "[...] há sempre o que é dito e o que não o é, um não dito que, entretanto, também se diz" (CHARAUDEAU, 2013, p. 9). Ressalta-se, por fim, que os estudos podem ser ampliados para outros estados, como também para outras experiências, principalmente na América Latina, que ainda carece de debates.

\section{REFERÊNCIAS}

\section{ABRÚCIO, L. F. Os avanços e os dilemas do} modelo pós-burocrático. São Paulo: FGV, 1998.

ACANDA, J. L. Sociedade civil e hegemonia. Rio de Janeiro: Ed. da UFRJ, 2006.

ALVES, M. A.; GOMES, M. V. P.; SOUZA, C. L. M. Análise do Discurso no Brasil: Será ela crítica? In: XXX ENCONTRO DA EnANPAD. Anais... Salvador, ANPAD, 2006.

AMORIM, A. P. O desafio do encontro da opinião pública democrática com a soberania popular: uma defesa republicana do direito de pronunciar a liberdade. Mediação, v. 15, n. 17, 2013.
ANASTASIA, A. A. Antecedentes e Origem do Choque de Gestão. In: VILHENA, R.; MARTINS, H. F.; MARINI, C.; GUIMARÃES, T. B. O Choque de Gestão em Minas Gerais: Políticas da Gestão Pública para o Desenvolvimento. Belo Horizonte: Editora UFMG, 2006.

ANDREWS, C. W.; KOUZMIN, A. O discurso da Nova Administração Pública. Lua Nova, n. 45, p. 97-129, 1998.

ARENDT, H. A condição humana. 11. ed. Rio de Janeiro: Forense Universitária, 2010.

BERNARDI, M. M. E.; CAMPOS, E. S. A. A função estratégica dos cargos de comissão: a experiência de Minas Geraiscomos Especialistas de Políticas Públicas e Gestão Governamental (EPPGGs) e os Empreendedores Públicos. In: IV Encontro de Administração Pública e 
Governança da ANPAD, IV. Anais. Vitória. 2010.

BERNARDI, M. M. E.; GUIMARÃES, T. B. Empreendedores Públicos: uma experiência de gestão estratégica de pessoas na administração pública do Estado de Minas Gerais. Congresso Internacional Del CLAD sobre La Reforma Del Estado y La Administracion Pública, Anais, Argentina, 13, 2008.

BITTAR, F. S. O.; BASTOS, L. T.; MOREIRA, V. L. Reflexões sobre o empreendedorismo: uma análise crítica na perspectiva da economia das organizações. Revista de Administração da UFSM, v. 7, n. 1, pp. 65-80, 2014.

BOX, R. C. Running government like a business - Implications for public administration theory and practice. American Review of Public Administration, v. 29, n. 1, p. 19-43, 1999.

BOX, R. C., MARSHALL, G. S., REED, B. J., \& REED, C. M. New public management and substantive democracy. Public Administration Review, v. 61, n. 5, p. 608-619, 2001.

BRESSER-PEREIRA, L. C. Reforma do Estado para a Cidadania. São Paulo: Editora 34, 1998.

CAMPOS, E. S. A.; BERNARDI, M. M. E. Comparação de rendimentos público privados e a carreira de EPPGG e Minas Gerais: uma defesa da diferenciação na gestão de pessoas do setor público. In: XXXII Encontro da ANPAD, XXXII. Anais. Rio de Janeiro. EnANPAD/ANPAD. 2008.

CARINHATO, P. H. Neoliberalismo, Reforma do Estado e Políticas Sociais nas últimas décadas do século XX no Brasil. Aurora, ano II, n.3, 2008.

CARRIERI, A. P.; SOUZA, E. M.; AGUIAR, A. R. C. Trabalho, violência e sexualidade: estudo de lésbicas, travestis e transexuais. Revista de Administração Contemporânea, v. 18, n.1, p. 78-95, 2014.

CHARAUdeAU, P. Discurso Político. São Paulo: Contexto, 2013.
COSTA, A. M.; BARROS, D. F.; CARVALHO, J. L. F. A dimensão histórica dos discursos acerca do empreendedor e do empreendedorismo. Revista de Administração Contemporânea, v. 15, n. 2, 2011.

DENHARDT, R. B.; DENHARDT, J. V. The New Public Service: serving rather than steering. Public Administration Review, v. 60, n. 6, p. 549-559, 2000.

DENZIN, N. K.; LINCOLN, Y. S. O planejamento da pesquisa qualitativa: teorias e abordagens. Porto Alegre: Artmed, 2006.

DIEFENBACH, F. E. Entrepreneurship in the Public Sector: when middle managers create public value. Gabler research, Gabler Verlag Wiesbaden, 2011.

DIEFENBACH, T. New Public Management in public sector organizations: the dark sides of managerialistic enlightenment. Public Administration, v. 87, n. 4, p. 892-909, 2009.

DINIZ, E. Crise, reforma do Estado e governabilidade. Brasil (1985-95). Rio de Janeiro: FGV, 1997.

FAIRCLOUGH, N. Discurso e mudança social. Brasília: Universidade de Brasília, 2001.

FARAZMAND, A. The future of public administration: challenges and opportunities: a critical perspective. Administration \& Society, v. 4, n. 4, p. 487-517, 2012.

FILION, L. J. O empreendedorismo como tema de estudos superiores. Palestra proferida no Seminário A Universidade Formando Empreendedores. Brasília, Brasil, 1999.

FRIEDMAN, M. Capitalismo e liberdade. [sol.]: Arte nova, 1977.

GOMES, D. T. et al. Apresentação do processo de formação da estratégia: um estudo de caso em empresa inovadora. Revista de Administração da UFSM, v. 5, n. 3, pp. 413438, 2012. 
GRAMSCl, A. Cadernos do cárcere. Trad. Carlos N. Coutinho. Rio de Janeiro: Civilização Brasileira, 2000. V. 2.

GUIMARÃES, J.; AMORIM, A. P. A corrupção da opinião pública: uma defesa republicana da liberdade de expressão. São Paulo: Boitempo, 2013.

GUIMARÃES, T. B.; BERNARDI, M. M. E. Empreendedores Públicos no Governo de Minas Gerais: Registro de uma Experiência de Resultados. Belo Horizonte: Editora UFMG, 2010.

GUIMARÃES, T. B.; PORDEUS, I. A.; CAMPOS, E. S. A. (Orgs.). Estado para Resultados: Avanços no Monitoramento e Avaliação da Gestão Pública em Minas Gerais. Belo Horizonte: Editora UFMG, 2010.

HABERMAS, J. Direito e democracia: entre facticidade e validade. Rio de Janeiro: Tempo Brasileiro, 2011.

HABERMAS, J. Teoría de la acción comunicativa. Tomo I: racionalidad de la acción y racionalización social. Madrid: Taurus, 1987.

HAYEK, F. A. O Caminho da Servidão. Rio de Janeiro: Expressão e Cultura: Instituto Liberal, 1987.

HOOD, C. A Public Management for all Seasons? Public Administration, V. 69, n. 1, p. 3-19, 1991.

IMASATO, T.; MARTINS, P.E.M.; PIERANTI, O.P. Administrative Reforms and Global Managerialism: A Critical Analysis of Three Brazilian State Reforms. Canadian journal of Administrative Sciences, 2010.

KEINERT, T. M. M. Administração Pública no Brasil: crises e mudanças de paradigmas. 2. ed. São Paulo: Annablume/FAPESP, 2007.

KETTL, D. F. A Revolução Global: Reforma da Administração do Setor Público. In: BRESSERPEREIRA, L. C; SPINK, P. (ORG.). Reforma do
Estado e Administração Pública Gerencial. Rio de Janeiro: Editora FGV, 2006. p. 75-122.

KLEIN, N. A doutrina do choque: a ascensão do capitalismo de desastre. trad. Vania Cury. Rio de Janeiro: Nova Fronteira, 2008,

LEME, A. A. Neoliberalismo, globalização e reformas do Estado: reflexões acerca da temática. Barbarói, n. 32, 2010.

LOPES, H.M.; CAMPOS, E. S. A. Empreendendo - Programa Estado para Resultados. In: GUIMARÃES, T. B.; BERNARDI, M. M. E. (Orgs.) Empreendedores Públicos no Governo de Minas Gerais: Registro de uma Experiência de Resultados. Belo Horizonte: Editora UFMG, 2010.

MCCLELLAND, D. C.; BURNHAM, D. H. Power is the great motivator. Harvard Business Review, March-April, pp. 100-110, 1976.

MELO, I. F. Análise do Discurso e Análise Crítica do Discurso: desdobramentos e intersecções. Letra Magna, v. I, p. 01-02, 2009.

MINAS GERAIS. Lei Delegada 112, de 25 de janeiro de 2007. Dispõe sobre a organização e a estrutura da administração pública do poder executivo do Estado e dá outras providências. Belo Horizonte, 2007a. Disponível em: <http.// www.almg.gov.br>. Acesso em: 26 de nov. 2013.

MINAS GERAIS. Lei Delegada 174, de 26 de janeiro de 2007. Dispõe sobre o Grupo de Direção e Acessoramento do Quadro Geral de cargos de provimento em comissão e as funções gratificadas da Administração Direta do Poder Executivo, e dá outras providências. Belo Horizonte, 2007c. Disponível em: <http.// www.almg.gov.br>. Acesso em: 26 de nov. 2013.

MINAS GERAIS. Secretaria de Estado de Planejamento e Gestão. Plano Mineiro de Desenvolvimento Integrado 2007-2023. Belo Horizonte, 2007b. Disponível em: 〈http:// www.planejamento.mg.gov.br). Acesso em: 26 
nov. 2013.

MORAES, R. C. Reformas Neoliberais e Políticas Públicas: Hegemonia ideológica e redefinição das relações estado-sociedade. Educ. Soc., v. 23, n. 80, p. 13-24. 2002.

MORAIS, M. A. C.; VALADARES, J. L.; EMMENDOERFER, M. L. Meta-Análise da Produção Científica Internacional sobre Empreendedorismo no Setor Público: O que tem sido escrito acerca disso? In: XXXVII ENCONTRO DA ANPAD, XXXVII. Anais. Rio de Janeiro. EnANPAD/ANPAD. 2013. CD.

OSBORNE, D.; GAEBLER,T. Reinventando o Governo. Como o Espírito Empreendedor Está Transformando o setor público. Brasília: $\mathrm{MH}$ Comunicação, 1994.

PAES DE PAULA, A. P. Por uma nova gestão pública: limites e potencialidades da experiência contemporânea. Rio de Janeiro: Editora da Fundação Getúlio Vargas, 2005.

PAIVA, K. C. M.; COUTO, J. H. Qualidade de vida e estresse gerencial "pós-choque de gestão": o caso da Copasa-MG. Revista de Administração Pública, v. 42, n. 6, p.1189-1211, 2008.

PECI, A.; FIGALE, J.; OLIVEIRA, F. BARRAGAT, A.; SOUZA, C. Oscips e termos de parceria com a sociedade civil: um olhar sobre o modelo de gestão por resultados do governo de Minas Gerais. Revista de Administração Pública, v. 42, n. 6, p. 1137-1162. 2008.

PERREN, L.; JENNINGS, P. L. Government discourses on entrepreneurship: Issues of legitimization, subjugation, and power. Entrepreneurship Theory and Practice, v. 29, n. 2, p. 173-184, Mar 2005.

PORTO, C. A. F.; SILVEIRA, J. P. O Planejamento e a Gestão Estratégica e sua Função em Minas Gerais. In: GUIMARÃES, T. B.; PORDEUS, I. A.; CAMPOS, E. S. A. (Orgs.). Estado para Resultados: Avanços no Monitoramento e Avaliação da Gestão Pública em Minas Gerais. Belo Horizonte: Editora UFMG, 2010.
QUEIROZ, R. G. M.; CKAGNAZAROFF, I. B. Inovação no setor público: uma análise do choque de gestão (2003-10) sob a ótica dos servidores e dos preceitos teóricos relacionados à inovação no setor público. Revista de Administração Pública, v. 44, n. 3, p. 679-705, 2010.

RAMOS, A. G. A nova ciência das organizações: uma reconceituação da Riqueza das Nações. Tradução Mary Cardoso. Rio de Janeiro: Editora da FGV, 1981.

RESENDE, V. M.; RAMALHO, V. Análise de discurso crítica. São Paulo: Contexto, 2013.

ROBERTS, N. C; KING, P. J. Policy entrepreneurs: Their activity structure and function in the policy process. Journal of Public Administration Research and Theory, Vol. 1, n. 2, p. 147-175, 1991.

RODRIGUES, M. S.; DELLAGNELO, E. H. L. Do discurso e de sua análise: reflexões sobre limites e possibilidades na Ciência da Administração. Cadernos EBAPE.BR, v. 11, n. 4, p 621-635, 2013.

SADLER, R.J. Corporate entrepreneurship in the public sector: the dance of the chameleon, Australian Journal of Public Administration, V. 59, n. 2, p. 25-43, 2000.

SCHUMPETER, J. A. History of Economic Analysis. Nova York: Oxford University Press, 1954.

SECCHI, L. Modelos orgnanizacionais e reformas da administração pública. Revista de Administração Pública, v. 43, n. 2, p. 347-69, 2009.

SOUZA, R. B. "Mais Brasil para mais brasileiros": campanha ou marketing político? Um estudo discursivo crítico. Universidade Federal de Viçosa (Dissertação de Mestrado em Letras), 107p, Viçosa, 2012.

SPINK, P. Redução da pobreza e dinâmica locais. Rio de Janeiro: FGV, 1998. 
TENÓRIO, F. G. (Re) Visitando o conceito de gestão social. In: SILVA JUNIOR, J. T. et al. (Org.). Gestão social: práticas em debate, teorias em construção. Fortaleza: Imprensa Universitária, 2008.

TENÓRIO, F. G. Tem razão a administração? Ensaios de teoria organizacional. 3. ed. Ijuí: Editora Unijuí, 2008.

THOMPSON, J. B. Ideologia e cultura moderna: teoria social crítica na era dos meios de comunicação de massa. Petrópolis: Vozes, 2009.

VALADARES, J. L.; EMMENDOERFER, M. L. Cargos de Livre Nomeação: Reflexões com Base no Empreendedor Público em um EstadoMembro do Brasil. Revista de Administração Contemporânea, v. 16, n. 5, p. 723-743, 2012.

VALADARES, J. L.; EMMENDOERFER, M. L. O Uso de Leis Delegadas no Brasil: Uma Análise com Base no Modelo de Skowronek. In: XXXVII ENCONTRO DA ANPAD, XXXVII. Anais... Rio de Janeiro: ANPAD, 2013.

VALADARES, J. L.; SOUZA, G. C.; VILAS BOAS, A. A. O Resgate do empreendedor: uma discussão sobre a (re)incorporação do empreendedorismo no setor público à luz de uma perspectiva crítica. XXXIX ENCONTRO DA ANPAD. Anais... Belo Horizonte, Minas Gerais: ANPAD, 2015.

VAN HELDEN, G. J.; JANSEN, E. P. New public management in Dutch local government. Local Government Studies, v. 29, n. 2, p. 68-88, 2003.

VASCONCELOS, K. E. L.; SILVA, M. C.; SCHMALLER, V. P. V. (Re)visitando Gramsci: considerações sobre o Estado e o poder. Revista katálysis, v. 16, n. 1, pp. 82-90, 2013.

VIEIRA, S. F. A.; MELATTI, G.; RIBEIRO. O Ensino de Empreendedorismo nos Cursos de Graduação em Administração: um Estudo Comparativo entre as Universidades Estaduais de Londrina e Maringá. Revista de
Administração da UFSM, v. 4, n. 1, pp. 288301, 2011.

VILHENA, R. Terceira Geração do Choque de Gestão em Minas Gerais: Gestão para a Cidadania $O$ Fortalecimento da Cidadania através de um Estado em Rede. Artigos do Conselho Nacional de Secretários de Estado de Administração - CONSAD de 29 de fevereiro de 2012. Disponível em: «http://www.consad.org. br. Acesso em: 24 abr. 2012b.

VILHENA, R.; MARTINS, H. F.; MARINI, C.; GUIMARÃES, T. B. O Choque de Gestão em Minas Gerais: Políticas da Gestão Pública para o Desenvolvimento. Belo Horizonte: Editora UFMG, 2006.

VOGEL, R. Framing and counter-framing new public management: the case of Germany. Public Administration, v. 90, n. 2, p. 370-392, 2012.

WOOD JÚNIOR, T.; PAULA, A. P. P. Pop Management: contos de paixão, lucro e poder. Organizações e Sociedade, v. 9, n. 24, p. 39-51, 2002. 